\title{
Ascaris lumbricoides Infection among Pupils of Primary Schools in Uzoagba, Ikeduru, Southeastern Nigeria: A Survey
}

Kizito Uzoma Ndugbu*

Department of Public Health Technology, Federal University of Technology, Nigeria

*Corresponding author: Kizito Uzoma Ndugbu, Department of Public Health Technology, Federal University of Technology, Nigeria, Tel: +23408032654963; E-mail: kizykn@gmail.com

Received date: November 12, 2018; Accepted date: November 22, 2018; Published date: November 27, 2018

Copyright: ( 2018 Ndugbu KU. This is an open-access article distributed under the terms of the Creative Commons Attribution License, which permits unrestricted use, distribution, and reproduction in any medium, provided the original author and source are credited.

\begin{abstract}
Objective: To access the presence and prevalence of roundworm among the study population.

Study design: A simple primary school based questionnaire was distributed to the pupils to determine the name, age, sex and sanitation situations in the schools and homes. Also, a total of 561 samples collected were processed using formal ether concentration technique.
\end{abstract}

Results: $2(0.3 \%)$ pupils from Abo and Umueme primary schools were positive for Ascaris lumbricoides. The sex distribution of the infestation showed a higher prevalence of $1(0.3 \%)$ among the females and none among the males. From the age group distribution, we saw that $1(0.8 \%)$ in the age group (5 to 13$)$ years was positive.

Conclusion: There is an unhealthy presence and prevalence of $A$. lumbricoides among the study population, particularly among the females who must carry out domestic chores and water fetching in an environment of open air pollution.

Keywords: Ascaris lumbricoides, Primary schools; Prevalence; Ikeduru; Nigeria

\section{Introduction}

Ascaris lumbricoides is an intestinal thread-like oviparous obligatory parasite. It (roundworm) is the largest nematode parastizing the human intestine. It belongs to the Ascaridocea family, and is a 'soiltransmitted' helminth. One becomes infected by ingesting fertilized eggs picked up from soil, food or drink contaminated by human faeces. Upon ingestion, the eggs begin a journey of parasiting that starts with the embryonated eggs reaching the small intestine, particularly the jejenum of man; where they develop into larvae. The larvae thus developed, quickly penetrates the gut wall, migrating to the liver; and the lungs via the blood stream [1]. In the lungs, there is a further crawl above the epiglottis to the pharynx and then a swallowing again that gets the worm into the digestive tract [2].

Children, particularly, get infected when playing in such polluted surroundings get the eggs from the soil into their fingernails; which the eventually put into their mouths $[3,4]$. Although all age groups showed infection in endemic areas, the incidence and intensity are most in the younger age brackets. This is probably seen as arising from variation in behavior and occupational activities between children and adults; including the development of acquired resistance [5]. Ascaris has been known to retard growth in children, consequent of the robbing of the nutritional status of the host while being causative to bowel contractions, appendicitis, peritonitis, liver abscesses, bronchopneumonia, and intestinal occlusion [6]. A. lumbricoides prevalence among children can usefully be used as an index of fecaloral route in a community as they form the most vulnerable age group who happen to live in environments of indiscriminate defecation, of places where human faeces are used as fertilizers; of situations where infected drinks and foods are consumed without the least patience to stall the rush of hunger or thirst with the wedge of proper hand washing or washing. As was pointed out [7], the high prevalence among the children is mostly as a result of the poor hygienic conditions they live in which increases the tendency of a vicious cycle of worm infestation endemicity. Of course, any effort at controlling and prevent the infestation of Ascaris must be by way of improved sanitation merged with treatment. This will involve discouraging rural dwellers, young children and households from using human faeces as fertilizers, and defecating in the open air, and eating unwashed foods [8].

\section{Subjects and Methods}

\section{Study area}

Uzoagba is one of the rural towns that make up Ikeduru local government area of Imo State, which has a density of $981.68 \mathrm{inh} . / \mathrm{km}^{2}$, and an area of $179 \mathrm{~km}^{2}$ Uzoagba has eleven villages (Umuagwu, Umueze, Umuomi, Amambaa, Umuehihie, Umualumaku, Nduhuobokwe, Umumkpee, Umueziogwu, Umueme and Abo) it has about 13,000 people. It boasts of many established and accomplished indigenes that include-teachers, doctors, lawyers, traders, businessmen and businesswomen. The natural vegetation is mainly tropical rainforest and the inhabitants are mostly farmers. Soil of the area are derived from derived from the coastal plain sands, and has a humid climate with mean annual rainfall greater than $2500 \mathrm{~mm}$ and annual temperature range of $26-30^{\circ} \mathrm{C}$. Rainfall pattern is bimodal, with July and September being peaks. The streams closer to some of the primary schools were used as sources of drinking water and refuse dumps. 
Page 2 of 3

\section{Sample size determination}

For this study, five primary schools were selected; namely Abo Community primary school, Umueme primary school, Umuagwu primary school, Umueze primary school and Obokwu primary school. The sample size was obtained by a random sampling of the pupils.

\section{Methods}

561 pupils were sampled at the end of 2 months. Each of the pupil was given a specimen tube and was given an instruction of bringing it back the next day with his/her early morning stool therein. The brought and received samples were taken to a laboratory and immediately processed. The concentration of the samples were done by formol-ether concentration technique, and of course demonstrated macroscopically and microscopically.

In the macroscopic demonstration, with naked eyes we looked out for the colour of the specimen, the consistency (whether it is formed, semi-formed, soft or watery), blood stains, mucus, and the presence of adult worms. The findings were noted on a log chart under each pupil's name. Also, recorded were the socio-demographic characteristics of the pupils in the study area.

Carrying out the microscopic demonstration, the samples were analyzed using the formol-ether concentration technique [9] as follows: With an applicator stick, $1 \mathrm{~g}$ of the stool was emulsified in $4 \mathrm{ml}$ of $10 \%$ formol-ether contained in a tube. Additional $4 \mathrm{ml}$ formol-ether was added and homogenized. The emulsified faeces were sieved and collected in a tube. The suspension was transferred to a centrifuged tube into which $4 \mathrm{ml}$ of diethyl ether was added. The tube was stoppered and mixed for 1 minute. The stopper was loosened and the tube centrifuged at $1000 \mathrm{~g}$ for 1 minute; after centrifuging, the faecal debris was loosened and decanted along with the ether and formal water; leaving the sediment at the bottom of the tube. The bottom of the tube was then tapped to re-suspend and msix the sediment. The sediment was placed on the slide, covered with cover slip and examined microscopically.

\section{Results}

Out of the 561 samples collected and examined in this study, $2(0.3 \%)$ indicated positive for Ascaris. The age group of 5 to 13 years had the highest prevalence $(0.4 \%)$, while age group (14 and above) indicated no prevalence. Sex distribution of the infection showed the highest prevalence $(0.3 \%)$ among the females than in the males.

\begin{tabular}{|l|l|l|l|}
\hline School & No. Examined & No. Positive & Percentage \\
\hline Umuagwu Prim. Schl. & 78 & 0 & 0.0 \\
\hline Abo Comm. Prim. Schl. & 139 & 1 & 0.7 \\
\hline Obokwu Prim. Schl. & 133 & 0 & 0.0 \\
\hline Umueze Prim. Schl. & 92 & 0 & 0.0 \\
\hline Umueme Prim. Schl. & 119 & 1 & 0.8 \\
\hline TOTAL & 561 & 2 & 0.3 \\
\hline
\end{tabular}

Table 1: Prevalence of Ascaris infection per school.

\begin{tabular}{|l|l|l|l|}
\hline Sex & No. Examined & No. Positive & Percentage \\
\hline
\end{tabular}

\begin{tabular}{|l|l|l|l|}
\hline Female & 364 & 1 & 0.3 \\
\hline Male & 197 & 0 & 0 \\
\hline TOTAL & 561 & 1 & 0.3 \\
\hline
\end{tabular}

Table 2: Sex distribution and prevalence of Ascaris infection among the study population.

\begin{tabular}{|l|l|l|l|}
\hline Age group & No. Examined & No. Positive & Percentage \\
\hline $5-8$ & 120 & 1 & 0.83 \\
\hline Sep-13 & 328 & 1 & 0.3 \\
\hline 13 and above & 113 & 0 & 0.0 \\
\hline TOTAL & 561 & 2 & 0.4 \\
\hline
\end{tabular}

Table 3: Age distribution and prevalence of Ascaris infection among the study population.

\section{Discussion}

Table 1 showed the prevalence of Ascaris among the study population. It indicated that $2(0.3 \%)$ of the pupils are positive for the infection. This agrees with varous submissions [10-12] that Ascaris has high prevalence among primary school children. Indeed, the obtained prevalence rate is clearly lower to the recorded $28 \%$ in Lagos, Lagos State [13]; and disagrees with 55.2\% obtained in Aba, Abia State [14].

From Table 2, we see that $1(0.3 \%)$ female was positive for Ascaris lumbricoides. This is in agreement with the discovery [15] that the prevalence of Ascaris was highest (91.6\%) among the female than the male. Also, the results agree with the findings [16] that there is a slight higher prevalence among girls than boys. However, our finding disagrees with other studies $[17,18]$ whose finding indicates higher prevalence among males compared to females. Surely, this could be as a result of the females been the main doers of domestic chores-cleaning this and that, going to the stream to fetch water and when pressed defecating around the river; and wantonly disposed to pick and eat wild fruits along the way (a common trend we observed).

Showing the age group distribution of Ascaris lumbricoides, Table 3 indicates infection rate on age group 5 to 13 years of $1.13 \%$. This agrees with the results in some studies $[11,15,19,20]$ that the infection is high among children below 13 years of age. The low prevalence from 14 years and above as observed $[21,22]$ could be as a result of higher level of awareness and good hygienic practices. We, thus, observed that the prevalence among the study population decreased with age.

\section{Conclusion and Recommendations}

Given the findings and observations, Ascaris lumbricoides has very high prevalence among children of primary school ages, children who contend with inadequate water supply, poor hygienic conditions and ignorance. Several limitations were encountered in the course of this survey. First, is funding. Given that they study is self-funded, we ran out of fund along the way, and so we had to borrow. Second limitation is reporting bias due to survey fatigue. Participating pupils were interviewed up to ten different times over. The interview format was the same each visit and respondents could have omitted some questions in order to shorten the interview times. In order to mediate 
Citation: Ndugbu KU (2018) Ascaris lumbricoides Infection among Pupils of Primary Schools in Uzoagba, Ikeduru, Southeastern Nigeria: A Survey. J Health Educ Res Dev 6: 287. doi:10.4172/2380-5439.1000287

Page 3 of 3

potential fatigue, enumerators worked with the same pupils each in order to develop a relationship with the respondents.

Despite these limitations, the results of this study contribute to a growing body of literature on ascaris infection of pupils in low-income areas. This study has considered several knowledge and attitude factors that assist in understanding infection outcomes of Ascaris among pupils owing to poor personal and environmental hygiene habits.

Thus, there is need to medically attend to the persons infected to control the spread. There is equally a greater need to prevent the infection by educating the people, especially rural dwellers on the importance of proper hygienic practices like hand-washing, fruits and food and vegetable washing, discouragement from open air defecation and use of human faeces as fertilizers.

\section{Acknowledgements}

A special thanks goes to the primary schools and pupils for the cooperation they gave throughout the period of the survey.

\section{References}

1. Aguilar I, Galbes H (2012) Encyclopedia of health and education for the family. pp: 130-131.

2. Arora DR, Arora BB (2012) Medical parasitology. pp: 192-195.

3. Dyek ND (2001) Prevalence of eggs and cysts of parasites under the fingernails of primary school pupils in Samani Zaria, Nigeria. MSc Thesis, Ahmadu Bello University, Zaria.

4. Sawyer WA (1995) Factors that influence the rate of incidence of ascaris infection. Am J Hyg 5: 790-817.

5. Park K (2009) Preventive and social medicine. pp: 214-215.

6. Higgs DA, Jenkins P (1984) Human intestinal parasites in areas of Indonesia. Annl Trop Med Parast 78: 637-641.

7. Auta T, Kogi E, Oricha O, Audu K (2013) Studies on the intestinal helminths infection among primary school children in Gwagwalada, Kaduna, North Western Nigeria. J Bio Agr Healthcare.

8. Bethony J, Brookes S, Albonico M, Geiger SM, Loukas A, et al. (2006) Soil transmitted helminth infections. Lancet 367: 1521-1532.
9. Cheesbrough $\mathrm{M}$ (2000) District laboratory practice in tropical countries. Cambridge University Press, pp: 209-211.

10. Chukwuma ME, Ekejindu IM, Agbakoba NR, Ezeagwuna DA, Anaghalu IC, et al. (2009) The prevalence and risk factors of geohelminth infections among primary school children in Ebenebe town, Anambra state, Nigeria. Int J Epidemiol 4: 211-215.

11. Damen JG, Luka J, Biwan EI, Lugos M (2011) Prevalence of intestinal parasites among pupils in rural North Eastern Nigeria. Niger J Med 52: $4-6$.

12. Ekpenyong EA, Eyo EJ (2008) Prevalence of intestinal helminths infection among schooling children in tropical semi-urban community in Igbo-Eze South, Enugu state, Nigeria. Animal Research International.

13. Salake AA (2011) Effects of portable water availabilty on intestinal parasitism among rural school children with sewage disposal facilities in the Midum and Owutu sub-urban community of Lagos state, Nigera. Niger Med Pract 39: 30-50.

14. Agwu NA (2001) Incidence of intestinal helminthiasis in school children in Aba urban city, Abia state. J Int Env Health Hu Dev 1: 47-51.

15. Higgins DA, Jenkins P (1984) Human intestinal parasites in areas of Indonesia. Annl Trop Med Parast 78: 637-648.

16. Jumbo GTA, Egah DZ, Akuson JT, Mbaawuga EM (2007) Human intestinal parasitism in rural settlement of Northern Nigeria, a survey. Niger Med Pract 2: 48-54.

17. Dyek ND (2001) Prevalence of eggs and cysts of parasites under the fingernails of primary school pupils in Samani Zaria, Nigeria. MSc Thesis, Ahmadu Bello University, Zaria.

18. Lucas AO, Gilles HM (2003) Short textbook of public health medicine for the tropics. pp: 77-79.

19. Montiel JA, Carillo RC, Flores FJ (2003) Ascardiasis vesicular a sociala hepatitis aguda. Manejo Conservador 71: 314-318.

20. Park K (2005) Park's textbook of preventive and social medicine. Preventive Medicine in Obstet, Paediatrics and Geriatrics.

21. Person V, Ahmed F, Gebre G, Medhim M (2000) Relationship between vitamin a, iron status and helminthiasis in Bangladesh school children. Pub Health Nutr 3: 83-89.

22. Rajeswani B, Sinnaih B, Hussein H (1994) Socio-economic factors associated with intestinal parasites among children learning in Gombak Malaysia. Asia Pac Health 7: 21-25. 